\title{
CLASSIFICATION OF CROP-SHELTER COVERAGE BY RGB AERIAL IMAGES: A COMPENDIUM OF EXPERIENCES AND FINDINGS
}

\author{
Claudia Arcidiacono, Simona M.C. Porto
}

\section{Introduction}

In recent times protected cultivations have registered a rapid growth worldwide where the area of plastic greenhouses exceeds 500,000 ha. This growth is more evident in east Asia as well as in the Mediterranean basin where the plastic greenhouse area is over 130,000 ha [Agüera 2008; Agüera 2009]. Within the Mediterranean basin, south-eastern Sicily represents one of the most intensively cultivated area with crop shelters reaching over 7,000 ha of greenhouse coverings mainly located in the coastal areas of the territory [ISTAT 2000]. In this territory crop shelters are mainly plastic greenhouses or tunnels used for horticultural and floricultural breeding as well as plastic coverings for vineyard pergolas.

It is widely recognized that the anthropic load due to intensive agricultural production, together with other kinds of loads (e.g. road network, and urban and rural buildings), contribute to environmental changes by acting on different factors (e.g. soil morphology, soil chemical and physical composition, hydrological regime, spring water quality, operator's and consumer's health, and quality and functionality of the rural landscape) [Cascone 1992; Rogge 2008]. To reduce these negative effects on the environment, suitable methodologies and techniques require a more precise knowledge of crop-shelter localization and surface extent as well as their changes over time. This knowledge can be acquired by analyzing specific thematic cartography that, if available, is often difficult to update because of the temporary character of this type of buildings. In this regard, the production of thematic layers regarding crop shelter coverage may be assisted by processing the information contained in remote sensing images. In agricultural studies, image

Paper received 30.11.2009; accepted 01.06.2010

Claudia Arcidiacono, associate professor, carcidi@unict.it, SIMONA M. C. PorTo, Phd, University of Catania, Department of Agricultural Engineering, via S. Sofia 100 - 95123 Catania (Italy)

All authors of this research paper have equally participated in the planning, execution, and analysis of this study. analysis of aerial or satellite images has awoken the interest of researchers and it is currently applied in different fields, e.g. to analyze vegetation [Bitelli 2005; Boccia 2006; Carvajal 2006; Fiorentino 2006; Leone 2006; Sugiura 2005], for forestal inventory [Boyd 2005], to distinguish different plant typologies and classify soil use and soil coverage [Clark 2001; Townsend 2001; Langley 2001], to study biological parameters such as leaf area index, epigeal biomass, evapotraspiration, and physiological state [Chen J.H. 2002; Chen J.M. 2002; Wang 2005; Consoli 2006], to estimate agricultural productions [Clevers 1996], to highlight Change Detection at different scales [Lunetta 2002], and for fire monitoring [Li 2001].

Object recognition and feature extraction from remote sensing images (aerial orthophotos, satellite images, etc.) can be generally subdivided into manual digitizing or automated methods. For the development of the manual digitizing methods specialized technicians are needed in order to visually recognize and manually digitalize the feature classes of interest [Sönmez 2006; Jupiter 2007]. Though at present this is the most widespread approach to produce spatial data, yet it is a time-consuming operation and requires skilled technicians to carry out visual recognition of features. Therefore, this approach is rather far from Local Authorities' and market operators' requirements. The automated methods, instead, involve the construction of specific softwares or the use of inductive learning techniques. Within these techniques, the classification of digital images can be carried out by using two different analysis methods: the pixel-based method and the object-oriented method. Image classifications according to the pixel-based method are performed only on the basis of the spectral information contained in single pixels. In object-oriented methods, instead, the image analysis is carried out on regions, i.e. surfaces composed of groups of adjacent pixels and corresponding to real objects on the ground [Wuest 2009]. Besides the spectral data, the image classification according to object-oriented methods uses information concerning shape, size and texture of pixel aggregates [Gamanya 2007].

This paper summarizes the present state of the 
knowledge regarding the application of the abovementioned approaches for the recognition and the extraction of crop shelter features from remote-sensing images. Furthermore, this paper reviews the authors' experience gained in the achievement of accurate crop-shelter-coverage classification from aerial RGB digital images. Though this type of remote sensing images has less spectral information than the one acquired from satellites (Landsat, QuickBird, Ikonos, etc.), it results less expensive and much more available at the technical bureaus of the local authorities [Gennaretti 2009]. The authors' experience concerns the elaboration of methodologies suitable to recognize crop-shelter coverage applied to a wide region of south-eastern Sicily, characterized by intensive protected cultivation and lacking specific regulations for the building of these temporary constructions. The different experiences carried out to classify crop-shelter coverage aimed at the production of a thematic layer, supplementary to the information already contained in the technical cartography of the Province of Ragusa (e.g. buildings, road networks, and hydrography) which were used in other studies [Arcidiacono 2009] concerning the definition of land-use and environmental indicators.

\section{State of the knowledge}

An operator who classifies similar-looking objects contained within an image makes use of visual recognition in order to identify groups of elements homogeneous as regards colour, shape, texture, etc. Concerning digital images, the information needed to perform a classification is contained in the Digital Number (DN) of the pixels and in some characteristics of spatial regions constituted by pixel aggregation. If, for instance, the aim is to build a thematic map of the land use, the operator will associate some pixels of the analyzed image to specific classes of interest or information (e.g. water, woods, dry soil, and wet soil). The groups of pixels representative of the same information class are named 'spectral classes' and are homogeneous as regards the brightness values in the different spectral bands. When classifying a digital image it is necessary to establish a biunivocal relation between 'spectral classes' and related 'information classes'.

Automatic or semi-automatic classifications of digital images are carried out by means of image analysis methods. The most traditional classification approach utilizes only the pixel spectral characteristics for the recognition of objects in the image and it is well known as 'pixel-based approach', 'per-pixel approach' or 'spectral pattern recognition'. This approach makes use of two main inductive learning techniques to perform image classification: the 'unsupervised' and the 'supervised'.

In unsupervised classification the spectral classes are put together, at first, only on the basis of data numerical information and, only afterwards, they are as- sociated with information classes by the operator. To perform this classification suitable clustering algorithms are used which allow to assign experimental observations to a certain category or class. In clustering problems it is necessary to find both the mathematical laws which assign each experimental observation to the correct class and an adequate subdivision of the classes. In unsupervised classification, the operator generally specifies the number of clusters to be identified in the analyzed image. The end result of this iterative process produces a certain number of classes, equal to the number of clusters specified by the operator, which can be conveniently elaborated [Erdas Field Guide 2003; Gonzalez 2002].

In supervised classification, on the contrary, the information classes are firstly identified in order to determine the related spectral classes by which they are represented [Gonzalez 2002]. In this type of classification qualified operators (supervisors) identify areas which constitute homogeneous samples representative of specific classes of information, also named Areas Of Interest (AOI). The numerical information contained in all the spectral bands for each pixel belonging to each AOI, is elaborated in order to extract a single 'spectral signature' representative of this information. The set of spectral signatures constitutes the training sample which is used by suitable algorithms for the recognition of areas within the image having a similar spectral response to those identified for each AOI. Therefore, each pixel of the initial image is given a numerical information that identifies its assignment to a class. The capability of pixel-based approaches to perform the classification of remote sensing images fails when a certain number of pixels has similar spectral information. By analysing the feature space of an image, which is a two-dimensional scatter-plot diagram where the pixel values of two bands are plotted at a time, it is possible to highlight distinct spectral classes from overlapping ones. In this latter case, pixel-based classification fails since it is based on 'binary theory' which provides that one pixel is labelled only to a class or, otherwise remains not classified.

A different set of approaches to classify remote sensing images is based on an 'object-oriented', also called 'object-based', image analysis that combines spectral information with spatial one. Object-oriented approaches do not operate directly on individual pixels but on 'regions', also called 'objects', which are constituted by several pixels grouped together in a meaningful way. Image segmentation methods allow to subdivide an image into regions and the level of the segmentation depends on the problem to be solved. The main segmentation algorithms are subdivided into two categories: the first one based on the recognition of pixel-intensity discontinuity; the second one based on the recognition of the pixel-intensity similarity. The 'edge detection' approach belongs to the first class of methods and it is the most common algorithm used to detect discontinuity in an image, whereas 
'thresholding', 'region growing', and 'region splitting and merging', are examples of algorithms which group pixels on the basis of similar characteristics stated by predefined criteria [Gonzalez 2002]. Several computer softwares are produced to automate objectoriented analyses such as Definiens eCognition ${ }^{\circledR}$ or Feature Analyst ${ }^{\circledR}$.

As far as crop shelter classification is concerned, some studies were carried out in the Netherlands, China, Turkey, and Spain. In particular, in Westland, i.e. a province of Zuid Holland in the Netherlands, a study aimed to assess the reduction of agricultural land, highly characterized by crop shelters, due to the expansion of residential and industrial areas. Supervised classification of remote-sensing Landsat TM images was conducted to obtain land-use coverage of the study areas [Donnay 2003]. A study conducted in Shandong, i.e. a coastal province of eastern China, aimed to extract information on greenhouse coverage using an index model derived from TM digital data of Qingzhou City [Zhao 2004]. In Antalya, i.e. a region located in the Mediterranean coast of south-western Turkey, a study was performed to manage greenhouse information by creating a database systems based on remote sensing and geographic information systems. For this purpose, the greenhouse location was recognized by visual data analysis of satellite images, and geographical databases were created for each greenhouse [Sönmez 2006]. Finally, several studies were carried out in Campo de Níjar, i.e. a region located in the province of Almería (Spain), where an intensive agricultural production system exists and the greenhouse development and allocation is uncontrolled. Therefore, similarly to the situation in south-eastern Sicily (Italy), the detection and localization of greenhouses in south-eastern Spain is crucial information for local authorities to take decisions on natural resource management and for technician activities regarding the elaboration of agricultural development plans [Carvajal 2006; Carvajal 2007; Agüera 2007; Agüera 2008, Agüera 2009]. In these studies, methodologies for greenhouse coverage classification were proposed by analyzing high-resolution satellite images and using different image-analysis approaches such as neural networks (object-oriented analysis) and maximum likelihood classifier (pixel-based analysis).

\section{Authors' experience in crop shelter coverage classification}

\subsection{Study area, imagery and softwares}

The methodologies described in the following were applied to an area of south-eastern Sicily representative of intensive agricultural activities for protected cultivations. The methodologies suggest the choice of a study area, having a significant presence of crop shelter coverage, in which a sample area and two or more control areas are to be selected. In detail, the choice of the sample area should make it possible to identify and extract the greatest number of feature classes regarding the different typologies of crop shelters, whereas the control areas should be selected in order to carry out the accuracy assessment of the classification performed on the sample area.

The study area, located between the territories of the Municipalities of Ragusa and Scicli, has a surface of 4,500 ha and is sited between lat. $36^{\circ} 42^{\prime} 52^{\prime}$ 'and $36^{\circ} 45^{\prime} 18^{\prime \prime} \mathrm{N}$ and between long. $2^{\circ} 7^{\prime} 16^{\prime \prime}$ and $2^{\circ} 12^{\prime} 17^{\prime \prime}$ $\mathrm{E}$ (fig. 1). A sample area and two control areas, each of them having a surface of 210 ha, were selected within the study area (figs. 2, 3 and 4).

With the aim to perform the classification and the related accuracy assessment, the local authority of the considered territory, i.e. the Province of Ragusa, made the following digital images available:

- Aerial RGB orthophotos in raster format, acquired in 1999 by CGR (Compagnia Generale Ripreseaeree S.p.A.) through continuous strips, by using an airborne digital sensor ADS40. The georeferencing process was carried out during the aerial acquisition by an integrated Inertial/GPS system that provided the coordinates in a UTM system based on WGS84 Geodetic Datum. The georeferenced digital images were subsequently orthorectified and mosaicked. Thanks to accuracy improvement processes and image quality checks, the acquisition system allows to reach a 2 meter geometric precision.

- Technical Regional Cartography in vector format (TRC) of the study area, obtained from the above described aerial orthophotos.

- Thematic layer in vector format of the crop shelters located in the considered area, which is part of the Landscape Plan of the Province of Ragusa.

Though the available digital images are not up-todate, the validity of the proposed methodologies does not depend on the time of the aerial survey yet it is applicable straight forwardly to more recent images.

To identify and extract the feature classes related to crop shelters from RGB images it was necessary to convert the orthophotos, acquired by aerial sensors, to the digital graphic format handled by the software selected to perform the classification. In detail, the three images related to the single spectral band (Red, Green, Blue) were joined into a three-band file. Each layer of this file is composed of brightness values (from 0 to 255) related to the considered band. The obtained image was then corrected geometrically and radiometrically. Generally, the use of the geometric correction makes it possible to remove the image deformations due to the remote-sensing system whereas the radiometric correction reduces the error due to the influence of the atmospheric stratum between the sensor and the considered scene. Although the orthophotos were provided with a first geometric correction, applied to the remote-sensing images at the same time of the aerial survey, a second one was applied in order to transform the original coordinate system into 


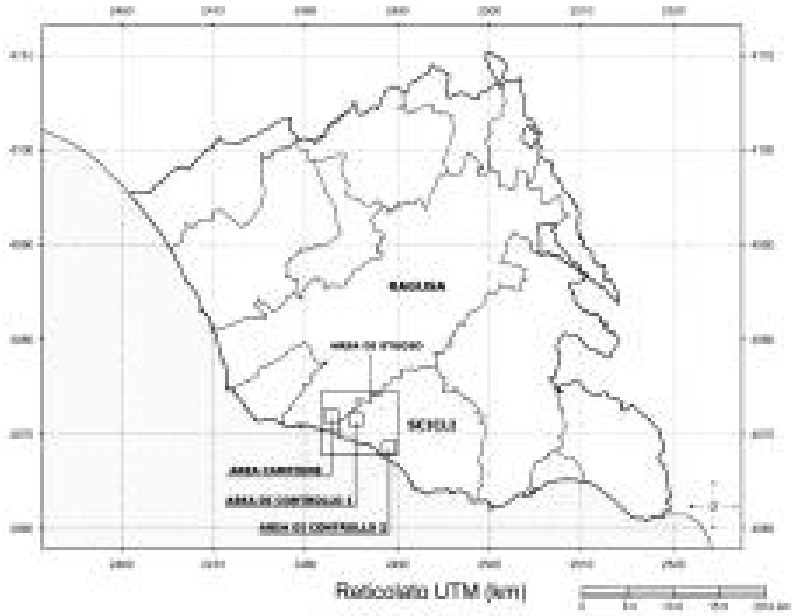

Fig. 1 - Localization of the study area, the sample area and the two control areas within the Province of Ragusa.

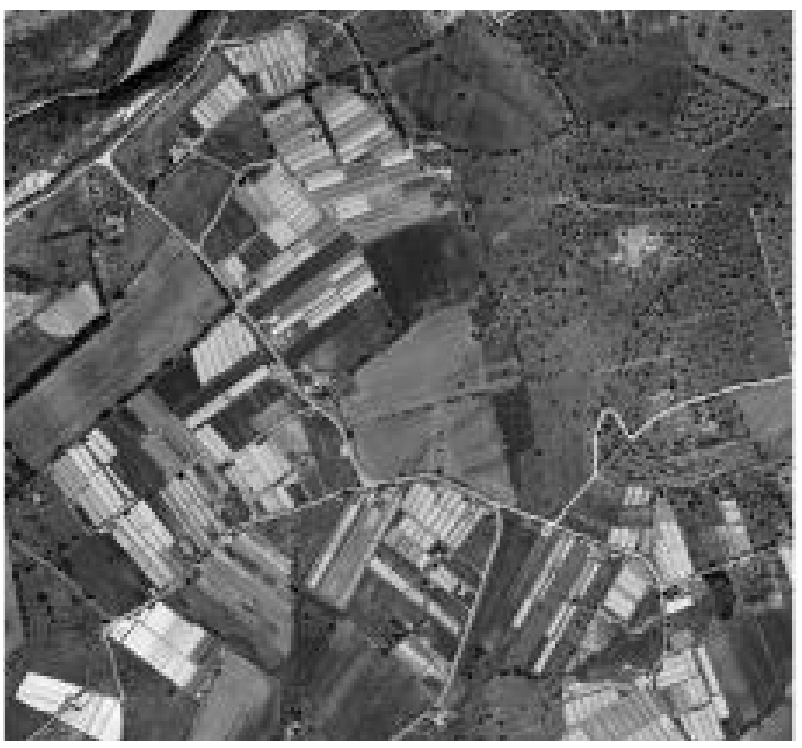

Fig. 3 - Aerial orthophoto of control area 1.

Gauss-Boaga Projection based on Roma40 Geodetic Datum, corresponding to the coordinate system of the TRC. This operation was carried out by choosing an adequate number of Ground Control Points. Finally, the radiometric correction made it possible to assign to each pixel of the acquired image the radiance value related to each observation band [Chander 2003; Chen 2005; Beisl 2006].

The classifications were carried out by using the commercial softwares Leica Erdas Imagine ${ }^{\circledR}$ and VLS Feature Analyst ${ }^{\circledR}$ for Leica Erdas Imagine ${ }^{\circledR}$.

\subsection{Pixel-based classifications}

\subsubsection{First experience}

In the first experience the recognition of crop shelter coverage was developed by carrying out a super-

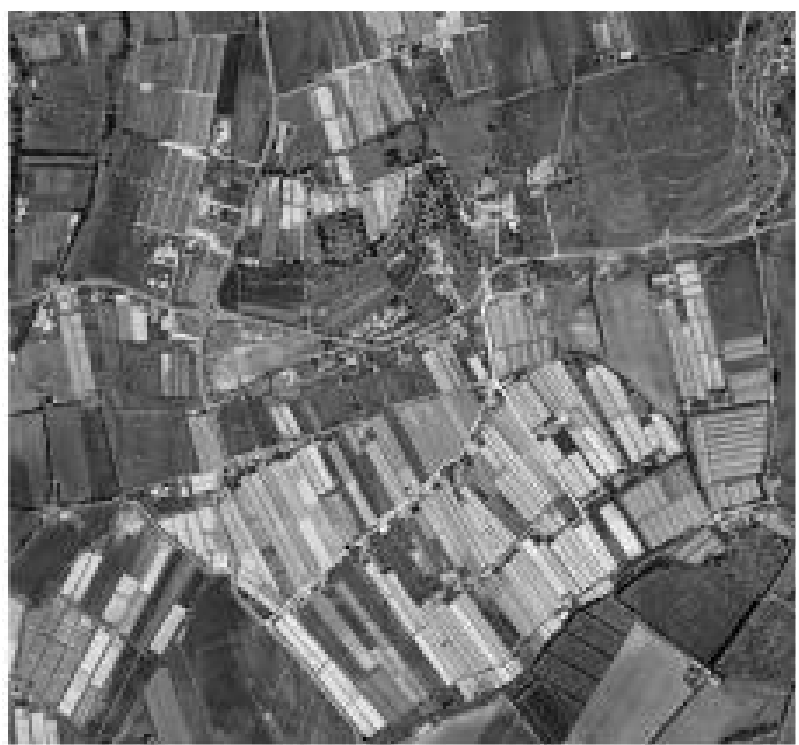

Fig. 2 - Aerial orthophoto of the sample area.

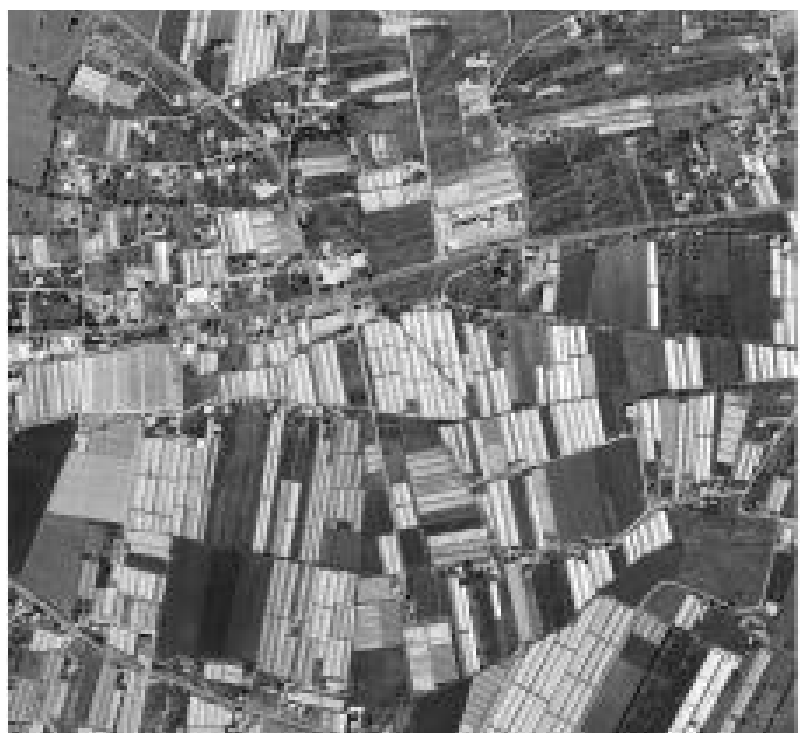

Fig. 4 - Aerial orthophoto of control area 2.

vised classification on the basis of the spectral signatures extracted by the application of clustering algorithms. Firstly a pre-processing of the image was conducted to enhance the visualization of crop-shelter contour.

In detail, the 'edge detection' algorithm was applied allowing to identify the contours by means of the Sobel filter [Gonzalez 2002]. The pre-processed image was then subtracted from the initial sample image in order to perform the unsupervised classification of the resulting image.

The unsupervised classification was performed by using the k-means algorithm or Iterative Self-Organizing Data Analysis Technique (ISODATA) [Marques de Sá 2001]. The algorithm produces a clustering solution for image pixels according to a pre-defined maximum number of clusters. In detail, the im- 
age is divided in a number $N$ of clusters $C\left(C_{1}, C_{2}\right.$, $\left.C_{3}, \ldots C_{N}\right)$ having $N$ centroids $\left(m_{1}, m_{2}, m_{3}, \ldots m_{N}\right)$, i.e. cluster means. The objective of the algorithm is to find the local minimum of the overall within-cluster distance by iteratively adjusting cluster centroids, $m_{k}$, and by assigning each pixel $x_{i}$ to the closest centroid [Marques de Sá 2001]:

$$
D=\sum_{i=1}^{K} \sum_{4}\left|x_{1}-m_{4}\right|^{2}
$$

The maximum number $N$ of clusters partitioning the image, the convergence threshold $T$, i.e. the maximum percentage of pixels which have their class values unchanged between iterations, and the maximum number of iterations $M$ to be performed, were fixed.

The algorithm determines the centroids of $N$ arbitrary clusters and computes the Euclidean spectral distances $D$ from each candidate pixel to each centroid as follows:

$$
D\left(x_{i}, m_{4}\right)=\left|x_{1}-m_{i}\right|^{2} \quad \forall k=1, \ldots
$$

The image is processed by the algorithm from the upper left corner to the left right one, pixel by pixel. Each pixel is assigned to the cluster having the closest mean. At the second iteration, according to the redefined spectral locations of the pixels in the cluster, the centroids are recalculated and used for defining the clusters in the next iteration. The process continues until the normalized percentage of unchanged pixels reaches the value of the assigned convergence threshold $T$.

By applying the above described algorithm, several classifications were carried out assigning different values to the variables which determine the maximum number of clusters, the convergence threshold and the maximum number of iterations. No significant improvement in the classification either by setting the maximum number of clusters greater than 30 or by fixing a number of iterations greater than 60 was observed. The convergence threshold was set equal to 99\% in order to minimize the error of pixel association to clusters.

From the classes obtained by the 'k-means' algorithm the spectral signatures (parametric signatures), corresponding to the groups of pixels which constitute the crop shelter features, were selected and merged whereas all the spectral classes related to other information (e.g. soil type, hydrography, and vegetation) were removed. These operations caused the production of unclassified areas ('empty islands') within the crop-shelter classified areas, due to the partial overlap between some spectral signatures corresponding to crop shelters and spectral signatures related to other feature classes. Therefore, the classified image was then subject to post-processing.

Some neighbourhood processing methods were performed with the aim to enhance and restore the classified image. In general, the neighbourhood analysis takes into consideration the context of each pixel. For instance, in case of a grey-scale image the principal approach in defining a neighbourhood of a pixel is to use a squared sub-image, referred to as a mask, centred at the same coordinate of the considered pixel. The centre of the mask is moved pixel by pixel from the top left corner to the bottom right one of the image and a specific neighbourhood function is applied at each location of the mask to produce the output. The function utilizes only the pixels in the area of the image spanned by the neighbourhood. Among the neighbourhood functions, the 'maximum' and 'majority' focal functions [Gonzalez 2002] were used in this first experience. Focal maximum was used in order to emphasize crop shelter feature class (class value 1) from the background (class value 0). This function, in fact, assigns to the pixel the greatest class value within the chosen mask, whereas the majority function is used in order to clean the classified image from 'salt and pepper' effects caused by classification errors. This function assigns to the pixel the class value that represents the majority of the class values in the window.

The spectral signature of the crop shelter class was saved to a file and then applied to perform the supervised classification of crop shelters located in the sample area and in the control areas. In detail, the file enclosed statistical parameters (e.g. mean and covariance matrix) of the pixels that are contained in the merged crop shelter coverage cluster. These parameters are used by the decision rule chosen to perform the supervised classification. As the histograms of the sample-area image bands have a nearly-normal distribution (fig. 5), the maximum likelihood decision rule was chosen to perform the supervised classification. This type of decision rule derives from the following Bayesian decision rule:

$$
d_{j}(x)=\ln P\left(\omega_{j}\right)-\frac{1}{2} \ln \left|C_{j}\right|-\frac{1}{2}\left[\left(x-m_{j}\right)^{3} C_{j}^{-1}\left(x-m_{j}\right)\right]
$$

where $P\left(w_{j}\right)$ denotes the probability that a particular pixel $\boldsymbol{x}$ comes from class $w_{j}, \boldsymbol{C}_{j}$ and $\boldsymbol{m}_{j}$ are the covariance matrix and the mean vector related to the pixels of the $w_{j}$ sample, respectively. If there is not an a priori knowledge of the probability $P\left(w_{j}\right)$, the default value of $P\left(w_{j}\right)$ is equal to 1 and the relation is called 'maximum likelihood'.

As the histograms of the control-area image bands do not have a nearly-normal distribution (fig. 5) the Mahalanobis distance decision rule was chosen to perform the supervised classification. The mathematical formulation of the Mahalanobis decision rule is defined as follows:

$$
d_{j}(x)=\left(x-m_{j}\right)^{f} C_{i}^{-1}\left(x-m_{j}\right)
$$

where the terms have the same significance described in equation (3). A pixel of the image is assigned to the class $j$ if $d$ is the lowest value. The Mahalanobis distance uses the covariance matrix within the minimum distance decision rule with the aim to determine different classes from highly varied clusters. 


\subsubsection{Second experience}

By performing visual-recognition operations on the sample area, suitable training samples were defined as Areas of Interest (AOIs) identified in both the initial RGB image and its associated Feature Space Image (FSI) [Erdas Field Guide 2003]. The FSI represents the scatter-plot diagram of one band of the RGB image versus another one of the remaining bands. In the methodology the red-blue FSI was chosen, i.e. in which the red spectral band is plotted in relation to the blue one. This FSI was selected among the others on the basis of its high pixel scattering which allowed the best identification of crop-shelter AOI.

The selected AOIs in the RGB image were of the following types:

- Polygons identifying the crop shelters.

- Contiguous pixels within the crop-shelter areas, collected by using an algorithm which identifies regions having similar spectral characteristics ('seed pixel method').

The AOIs selected in the FSI were defined by using the masking function of the software, which allowed to find in the scatterplot diagram the pixels having spectral characteristics corresponding to those selected in the RGB image by AOIs.

The AOI contours in the FSI were subsequently refined by iteratively using the masking function and the inquiry functions. In detail, the masking function applied to the AOIs of the FSI allows to make visible in the RGB image the pixel uncorrectly classified. These pixels were identified and discarded from the AOIs of FSI by connecting the RGB image with its FSI through the inquiry functions. Finally, a unique AOI was obtained by merging the crop-shelter AOIs of the FSI (fig. 6). By using this AOI to define a training sample, it was possible to create a non-parametric spectral signature for the classes regarding crop-shelter coverage. The supervised classification carried out by means of this type of spectral signatures did not depend on the statistics of the pixels, but only on the location of the pixels inside or outside the AOI in the FSI. The non-parametric decision rule used in the supervised classification was the 'feature space' rule and determined whether the pixel to be classified was located inside of the non-parametric AOI boundary or not [Erdas Field Guide 2003].

\subsection{Object-oriented classification}

The classification based on object-oriented methods was performed by means of the commercial software VLS Feature Analyst ${ }^{\circledR}$ for Leica Erdas Imagine ${ }^{\circledR}$ which uses inductive learning techniques in order to identify and extract feature classes from digital images in raster format. In detail, the software is a classificator that uses genetic algorithms suitable to automatically implement a set of neural networks having different architectures yet with the common aim to recognize the same feature classes [Blundell 2006].

Pre-processing was applied to the spatial domain of the initial image by using a filter which enhanced the image contrast [Gonzalez 2002]. The recognition and extraction of the feature classes related to crop shelter coverage were carried out by fixing adequate parameters for the learning process of the classificator. First of all, a mask of 9 pixels distributed according to the scheme depicted in figure 7 ('input representation'), generally recommended for the recognition and extraction of the feature classes having a block shape, was chosen. The algorithm places the central pixel of the mask on each pixel belonging to the training samples, storing the spectral information for each band. In this way, the algorithm generates a learning profile in which the characteristics of the classes related to the objects to be extracted are defined. The algorithm then places the mask central pixel over each pixel belonging to the spatial domain of the image to be classified and compares the actual information with that contained in the learning profile. If the analyzed pixel satisfies the characteristics of the learning profile it is assigned to the class to be extracted otherwise it is classified as background. The threshold value of 9 pixels for the mask depicted in figure 6 enabled the classificator to catch the reflectance changes due to the shape of crop-shelter covering.

Moreover, in order to remove the 'salt and pepper'

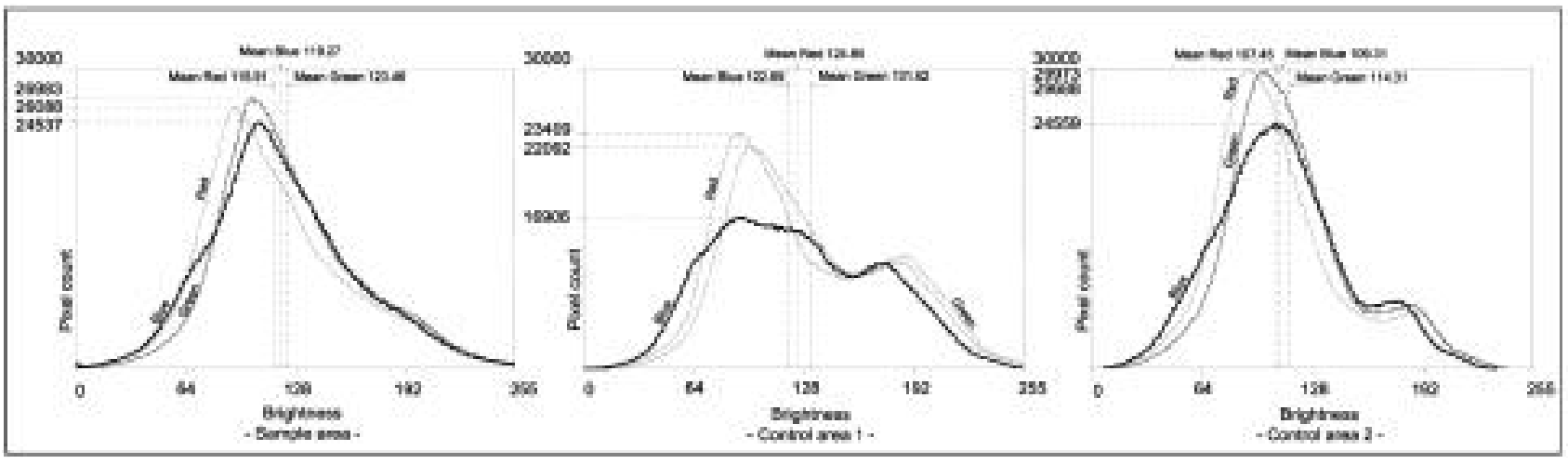

Fig. 5 - RGB histograms of the sample-area image and the two control-area images. 


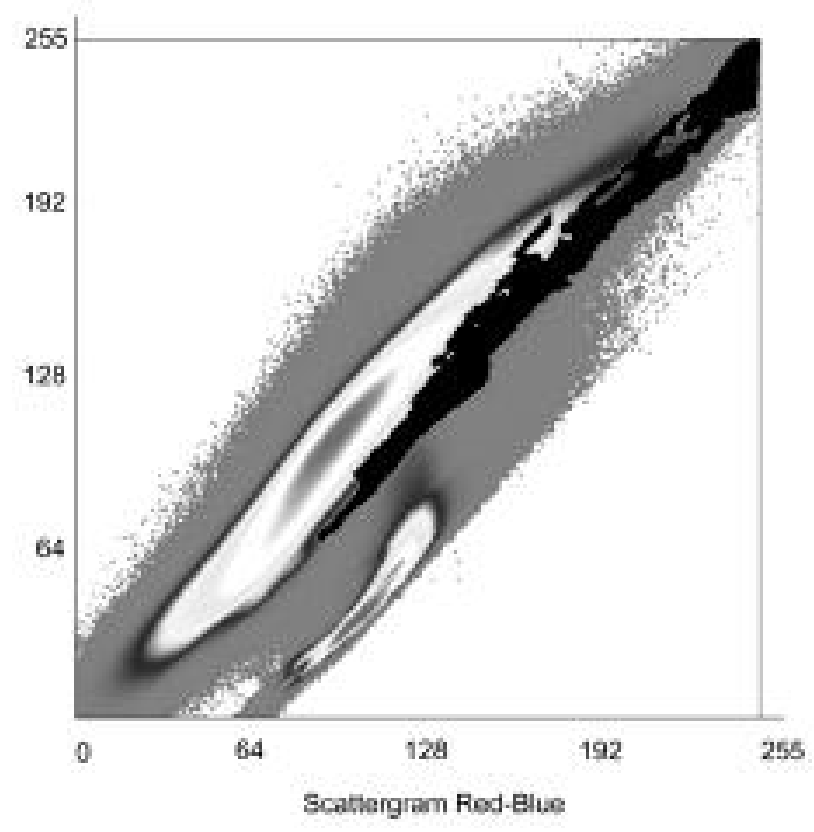

Fig. 6 - Feature space image of the study area and crop-shelter AOI (in black).

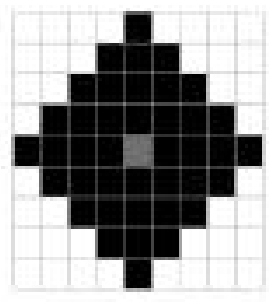

Fig. 7 - Mask used in the classification algorithm.

effect from the classification image, a threshold value equal to 90 for the aggregation function of the pixels was fixed. This value suits well the minimum size of the crop-shelter planimetric area.

The learning process was conducted by using error feedback techniques. In detail, both the correctly classified feature classes ('admitted') and the ones incorrectly recognized ('clutter removal') were repeatedly provided to the system, performing the next classification on the basis of the modified set of feature classes. The features, which were unrecognized due to overlap of crop-shelter spectral signatures with other feature ones, were conferred to the classificator ('missed feature adding') to be used in the next classification.
Crop shelters were classified by selecting a suitable number of training samples, representative of the different covering reflectances, and performing a number of classifications equal to the training samples. The results were then combined in a unique thematic map. This choice proved to be, once again [Arcidiacono 2008a; Arcidiacono 2008b; Arcidiacono $2008 \mathrm{c}$ ], better than performing a unique classification on the basis of a training sample representative of all crop shelter typologies ('multiclass extraction'). Therefore, the refinement of the results was conducted on the combined classification.

\subsection{Classification refinements and accuracy assess- ments}

The neighbourhood functions 'maximum focal function' and 'majority focal function' were applied to the classified images, with the aim to make the classified areas more uniform and to eliminate the "salt and pepper' effect from the image (figs. 8-13).

Classification phases of the proposed methodologies generally produce images where crop shelter coverage is overestimated, as it also includes part of the surfaces related to the roadways and the buildings. In detail, in this work the over estimation in cropshelter coverage is equal to about 8.43 ha, 6.59 ha, and 19.62 ha for the sample area and the two control areas, respectively. Though this misclassification of crop shelter coverage may be regarded as acceptable for some territorial analyses, nevertheless, in order to obtain an improvement of the classification result, the thematic layers of the road network and the built-up areas, obtained by the TRC, were superimposed (topographic overlay) and subtracted from the image. Furthermore, other post-processing operations were performed to sieve clusters characterized by fixed compactness values which fit greenhouse shape [Arcidiacono 2008a; Arcidiacono 2008b](figs. 8-13).

The accuracy level reached by the classifications was tested by means of a function which compares the classified images with control data acquired by performing ground surveys. In detail, the surface area of crop shelters, obtained by the classified images of the sample area and the two control areas, was compared with that of the layer in vector format contained in the Landscape Plan of the Province of Ragusa. In order to perform the accuracy assessment, it is necessary to select in a random way a set of reference pixels within the crop-shelter feature classes obtained by

\begin{tabular}{|c|c|c|c|c|c|c|c|c|c|}
\hline & \multicolumn{3}{|c|}{ Fint experietice } & \multicolumn{3}{|c|}{ Second experience } & \multicolumn{3}{|c|}{ Thind experiesce } \\
\hline & Sample area & $\begin{array}{l}\text { Conteral } \\
\text { area } 1\end{array}$ & $\begin{array}{c}\text { Control } \\
\text { area } 2\end{array}$ & $\begin{array}{c}\text { Sample } \\
\text { area }\end{array}$ & $\begin{array}{c}\text { Comtrol } \\
\text { area } 1\end{array}$ & $\begin{array}{c}\text { Control } \\
\text { area } 2\end{array}$ & $\begin{array}{c}\text { Sample } \\
\text { area }\end{array}$ & $\begin{array}{l}\text { Coetrol } \\
\text { area } 1\end{array}$ & $\begin{array}{l}\text { Conitrol } \\
\text { area } 2\end{array}$ \\
\hline $\mathrm{S}_{\mathrm{u}}^{\prime}(\mathrm{ha})$ & 58.4 & 34.2 & 63.5 & 58.4 & 42 & 63.5 & 58.4 & 34.2 & 63.5 \\
\hline S, flas & 45.8 & 28.5 & 67.4 & 48.9 & 346 & 64.0 & 52.0 & 34.3 & 65.2 \\
\hline$c(\mathrm{ha})$ & -12.6 & $-5 . T$ & +3.9 & -9.5 & +0.4 & +0.5 & -6.0 & +0.1 & -0.2 \\
\hline$A(\%)$ & 56.57 & $\$ 0.81$ & 74.00 & 35.88 & 92.60 & 92.95 & 83.15 & 94.73 & 93.83 \\
\hline
\end{tabular}

TABLE 1 - Comparison of the results obtained from the different methodologies applied in the described experiences: crop-shelter planimetric surface $\mathrm{S}_{\mathrm{cs}}^{\mathrm{v}}$ resulting from the vector layer, $\mathrm{S}_{\mathrm{cs}}$ resulting from classification methodologies, error $\varepsilon$ of crop-shelter planimetric surface in relation to the vector layer one, accuracy assessment $A$. 


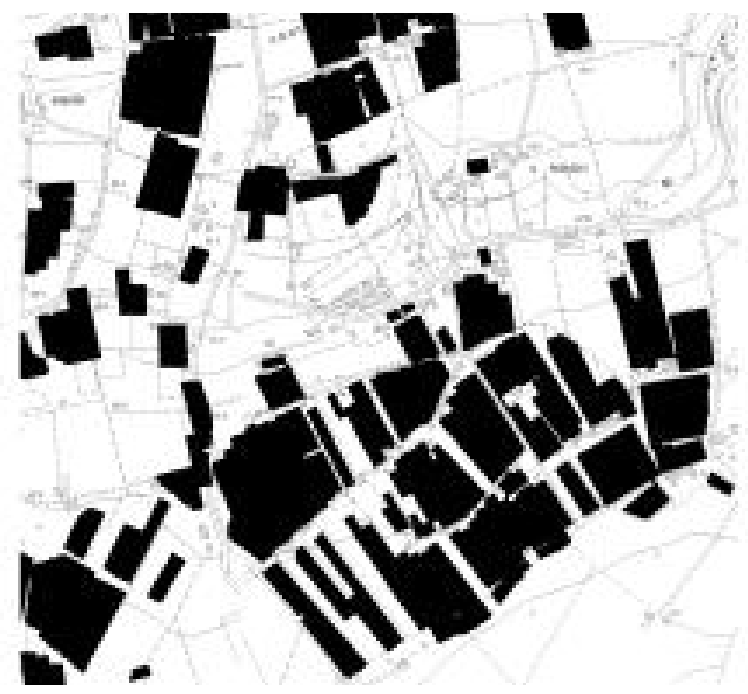

Fig. 8 - Overlay of the Landscape Plan to the Technical Regional Cartography of the sample area.

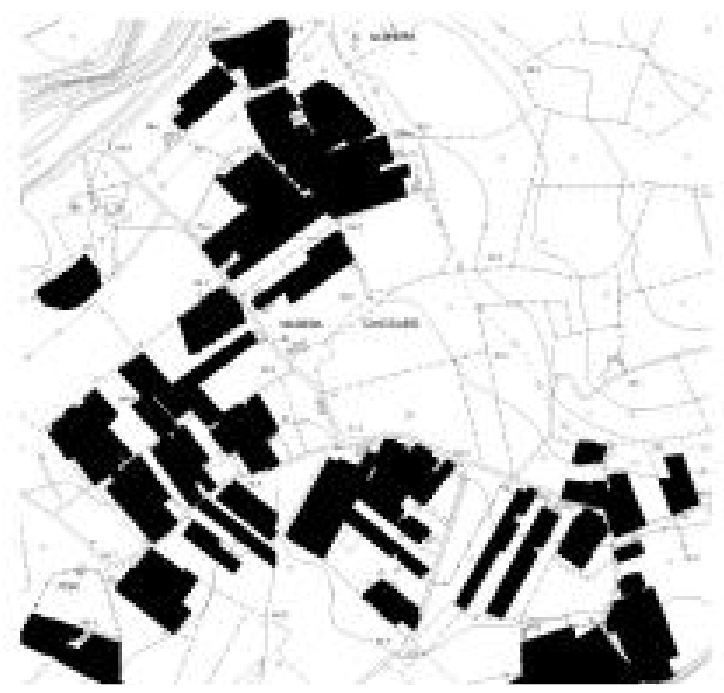

Fig. 10 - Overlay of the Landscape Plan to the Technical Regional Cartography of control area 1.

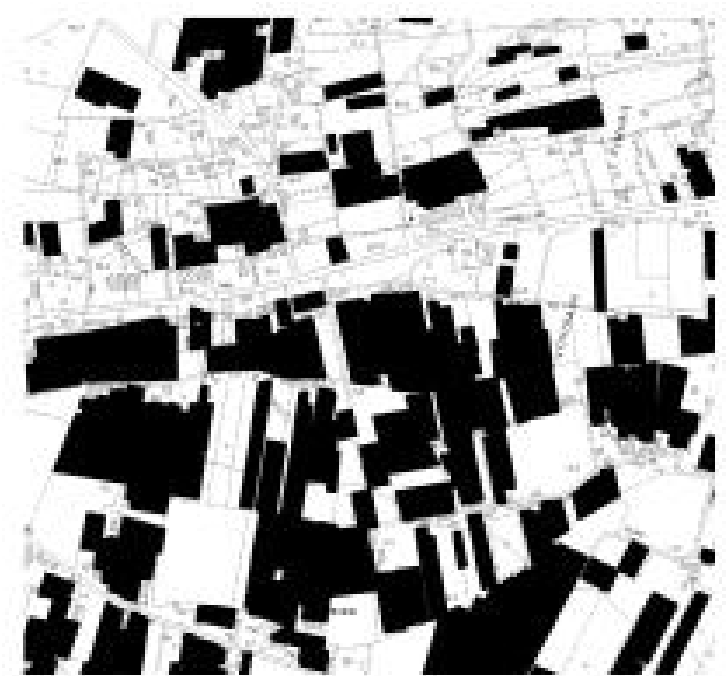

Fig. 12 - Overlay of the Landscape Plan to the Technical Regional Cartography of control area 2.

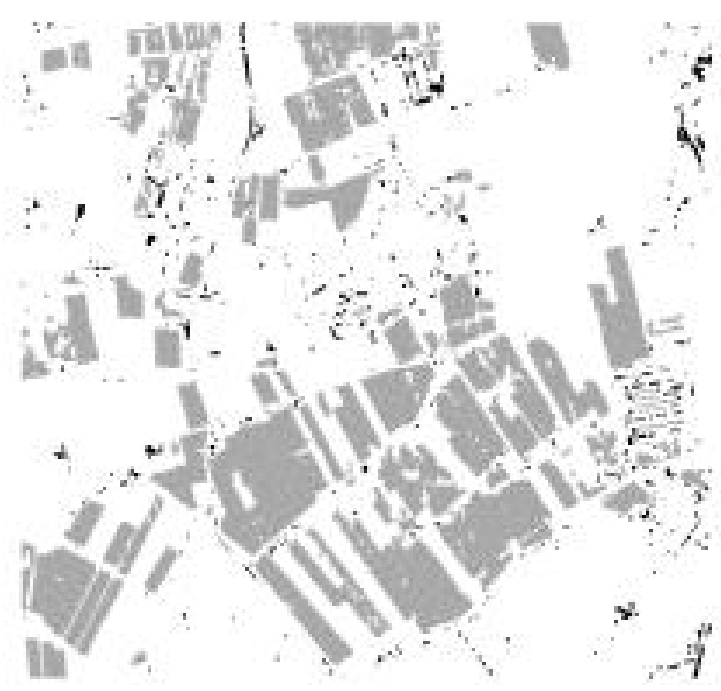

Fig. 9 - Sample area: results obtained by the application of the classification refinements. Crop shelter coverage (in grey), sieved clusters (in black).

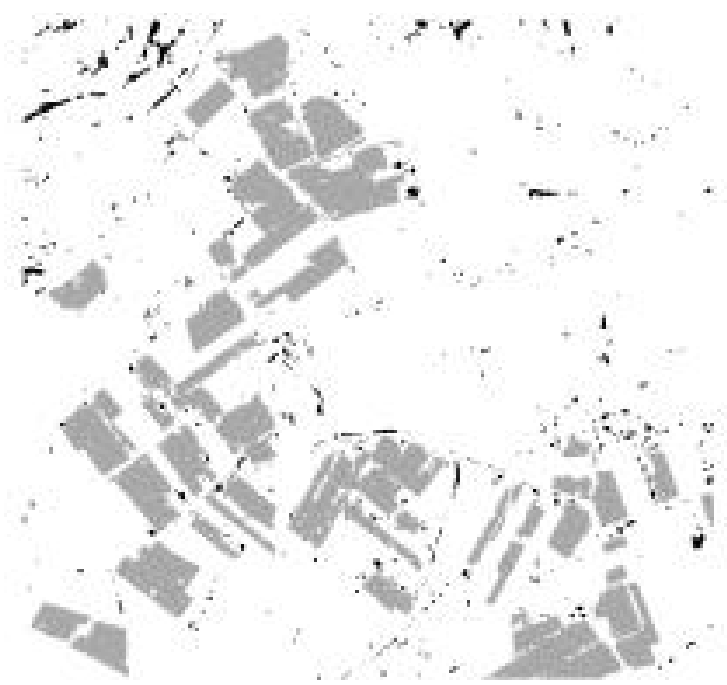

Fig. 11 - Control area 1: results obtained by the application of the classification refinements. Crop shelter coverage (in grey), sieved clusters (in black).

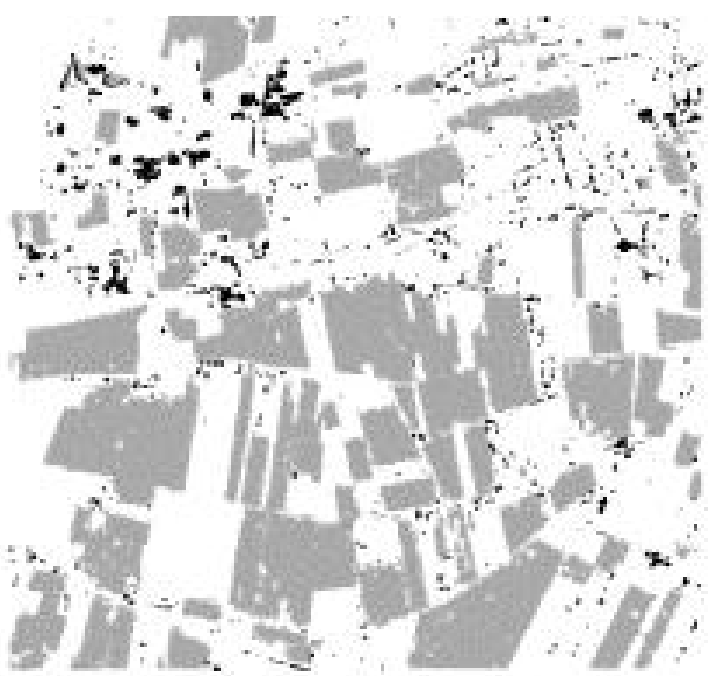

Fig. 13 - Control area 2: results obtained by the application of the classification refinements. Crop shelter coverage (in grey), sieved clusters (in black). 
the application of the classification methodology. The procedure counts the pixels corresponding to the crop shelters in the vector layer. The higher is the number of pixels in the feature classes which coincide with those in the vector layer, the better the classification accuracy results. As the crop shelter density in the sample area and in the first control area resulted comparable, the accuracy assessment of these classified images was carried out by choosing a number of pixel equal to 2,000. As, instead, the crop shelter density in the second control area resulted higher than that observed in the other two areas, the chosen number of pixels was equal to 5,500 .

\subsection{Comparison between 'pixel-based' and 'object- oriented' methodologies}

The results obtained by the methodology based on the object-oriented method were compared with those obtained by the two methodologies founded on the pixel-based method.

The comparison of the results ensuing from the application of these methodologies, showed a great reduction of the classification error attained by using the methodology based on the object-oriented method (tab. 1). In detail, for the sample area the accuracy of the results obtained by this methodology increases by $26.58 \%$ and $7.27 \%$ in comparison to the unsupervised and supervised pixel-based methodologies, respectively. For control area 1 the accuracy of the object-oriented methodology improves by $33.92 \%$ and $2.13 \%$ and for control area 2 it is $19.83 \%$ and $0.88 \%$ higher, in comparison to the unsupervised and supervised pixelbased methodologies, respectively. Moreover, the error in crop-shelter surface $\mathrm{S}_{\mathrm{cs}}$, computed by comparing the feature classes obtained by the classifications with those contained in the vector layer of the Landscape Plan of the Province of Ragusa, is very low in relation to the analyzed surfaces, following the methodology based on the object-oriented method, being lower than the $0.05 \%$ of the control-area surface areas.

Though the classification obtained by the application of the methodology based on the object-oriented method presents a higher accuracy in terms of both crop-shelter localization and estimation of their planimetric surface, still a weak point remains in distinguishing some feature classes related to crop shelters from others referring to some soil types. This weak point can be related to the occurring overlap of their spectral signatures in the visibile bands. In fact, a little separability of the spectral signatures emerged, in this case, between some soil types and some cropshelter feature classes, as it is observed from the related histograms (fig. 14). This limit appears intrinsic to the nature of the RGB images since the available spectral information is related only to the visible bands. Therefore, it can be inferred that the classification improvements obtained by the application of the methodology based on the object-oriented method is to be ascribed, rather than to the spectral information,

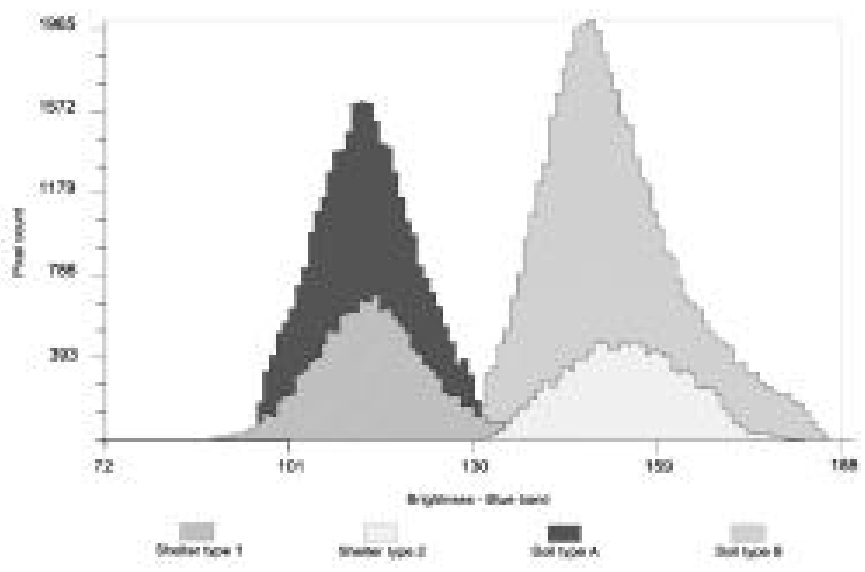

Fig. 14 - Overlapping histograms regarding soil types and cropshelter feature classes.

to the capability of the algorithm to manage spatial attributes.

\section{Conclusion}

In this paper the findings of several experiences on the definition and implementation of image processing methodologies based on pixel-based and objectoriented methods for crop shelter classification were analyzed and discussed. The comparison between the methodologies shows that the results attained by the pixel-based methodologies can be improved by using the object-oriented methodology, through the analysis of the correct choice of the model parameters for crop-shelter recognition and the application of refinement methods to the results.

Though a weak point intrinsic to the characteristics of RGB images still remains, the results can be regarded as very accurate in terms of both the localization and the quantification of the crop-shelter planimetric area. Furthermore, it was observed that the use of object-oriented methods produces not only more accurate results but also reduces the computational time of image classification.

The thematic maps obtained by the use of this image classification methodology may constitute a basic knowledge for environmental studies and for decision- making processes of local authorities concerning environmental issues.

Further improvements could be obtained by studying specific learning algorithms adequately adapted and implemented to identify and extract crop-shelter features.

\section{References}

Agüera F., Aguilar M.A., Aguilar F.J., Detecting greenhouse changes from QuickBird imagery on the Mediterranean coast. International Journal of Remote Sensing, 2007, 27(21), 4751-4767. 
Agüera F., Aguilar F.J., Aguilar M.A., Using texture analysis to improve per-pixel classification of very high resolution images for mapping plastic greenhouses. ISPRS Journal of Photogrammetry \& Remote Sensing, 2008, 63, 635-646.

Agüera F., Liu J.G., Automatic greenhouse delineation from QuickBird and Ikonos satellite images. Computers and Electronics in Agriculture, 2009, 66, 191-200.

Arcidiacono C., Porto S.M.C., Image Processing for the Classification of Crop Shelters, ISHS Acta Horticulturae, 2008a, 801, 309-316.

Arcidiacono C., Porto S.M.C., Classificazione degli apprestamenti di protezione delle colture (Semi-automatic classification of crop shelters based on image processing methodologies). Tecnica Agricola, 2008b, 3-14.

Arcidiacono C., Porto S.M.C., Metodologia object-oriented per la classificazione degli apprestamenti di protezione delle colture (Object-oriented methodology for crop shelter classification). Tecnica Agricola, 2008c, 15-23.

Arcidiacono C., Porto S.M.C., Analisi delle trasformazioni dei territori utilizzati per la serricoltura (Analysis of territorial transformations in protected cultivation areas). Estimo e territorio, 2009, 6, 36-43.

Beisl U., Absolute spectroradiometric calibration of the ADS40 sensor. ISPRS Commission Technique.I. Symposium, Marne-la-Vallée, FRANCE (03/07/2006) 2006, n. 181 (57 p.) [Document : 5 p.] (1/4 p.), pp. 14-18 [5 page(s) (article)]. Published on the Revue française de photogrammétrie et de télédétection.

Bitelli G., Ferrari C., Girelli V., Gusella L., Mognol A., Pezzi G., Integrazione di immagini multitemporali aeree e satellitari per lo studio del pattern della vegetazione dell'Appennino: un caso studio (Integration of multitemporal aerial and satellite images to study vegetation pattern in the Apennines: a case study). Atti della $9^{\circ}$ Conferenza ASITA, Catania, 15-18 novembre 2005, 371-376.

Blundell J.S., Opitz D.W., Object recognition and feature extraction from imagery: the Feature Analyst approach. 1st International Conference on Objectbased Image Analysis (OBIA 2006), Salzburg University, ustria, July 4-5, 2006

Boccia L., Recanatesi F., RIPA M.N., Metodologia speditiva finalizzata alla classifi-cazione dei tipi d'uso del suolo su area vasta a vocazione forestale (Expeditious metodology for classifying soil-use typologies over a forestal area). Rivista di Ingegneria Agraria, 2006, 2, 11-22.

Boyd D.S., Danson F.M., Satellite remote sensing of forest resources: three decades of research development. Progress in Physical Geography, 2005, 29(1), 1-26.

Carvajal F., Crisanto E., Aguilar F.J., Agüera F., Aguilar M.A., Greenhouses detection using an artificial neural network with a very high resolution satellite image. ISPRS Technical Commission II Symposium, Vienna, July 12-14, 2006, 37-42.

Carvajal F., Agüera F., Aguilar F.J., Aguilar M.A., Influence of atmospheric correction on greenhouses detection from Quickbird images. Annual Conference 2007 of Remote Sensing and Photogrammetry Society on 'Challenges for Earth Observation: Scientific, Technical and Commercial', Newcastle upon Tyne, 11-14 September 2007.

Cascone G., Di Fazio S., Effetti sull'ambiente degli insediamenti serricoli ad alta densità (Effects on environment due to high-density crop shelters). Colture protette, 1992, 11, 73-81.

Chander G., Markham B., Revised Landsat-5 TM radiometric calibration procedures and postcalibration dynamic ranges. IEEE Transactions on Geoscience and Remote Sensing, 2003, 41(11), 2674-2677.

Chen J.H., Kan C.E., Tan C.H., Shih S.F., Use of spectral information for wetland evapotraspiration assessment. Agricultural Water Management, 2002, 55: 239-248.

Chen J.M., Pavlic G., Brown L., Cihlar J., Leblanc S.G., White H.P., Hall R.J., Peddle D.R., King D.J., Trofymow J.A., Swift E., Van Der Sanden J., Pellikka P.K.E., Derivation and validation of Canada-wide coarse-resolution leaf area index maps using high-resolution satellite imagery and ground measurements. Remote Sensing of Environment, 2002, 80, 165-184.

Chen X., Vierling L., Deering D., A simple and effective radiometric correction method to improve landscape change detection across sensors and across time. Remote Sensing of Environment, 2005, 98, 63-79.

Clark P.E., Seyfried M.S. and Harris B., Intermountain plant community classification using Landsat TM and SPOT HRV data, Journal of Range Management, 2001, 54, 152-160.

Clevers J.G.P.W, van Leeuwen H.J.C., Combined Use of Optical and Microwave Remote Sensing Data for Crop Growth Monitoring. Remote Sensing of Environment, 1996, 56, 42-51.

Consoli S., D’Urso G., Toscano A., Remote sensing to estimate ET-fluxes and the performance of an irrigation district in Southern Italy. Agricultural Water Management, 2006, 81, 295-314.

Donnay J,. Barnsley M J, Longley P A. Remote sensing and urban analysis. Taylor and Francis, 2003, London and New York.

Erdas Field Guide ${ }^{\mathrm{TM}}$. Erdas Inc., 2003, Atlanta (Georgia).

Fiorentino C., Tarantino C., Castrignanò A., Pasquariello C., Uso dell'informazione spaziale per il miglioramento della classificazione (Use of spatial information to improve classification results). Proceedings of the X Conference ASITA, $14^{\text {th }}-17^{\text {th }}$ November 2006, Bolzano.

Gamanya R., De Maeyer P., De Dapper M., An automated satellite image classification design using object-oriented segmentation algorithms: A move towards standardization. Expert Systems with Applications, 2007, 32, 616-624.

Gennaretti F., Pelorosso R., Ripa M.N., Recanatesi F., Leone A., Mappe di copertura delle terre da foto aeree: metodologia object-oriented per lo studio delle dinamiche del paesaggio (Soil coverage maps from aerial photographs: object-oriented methodology for landscape dynamic studies). IX Convegno Nazionale dell'Associazione Italiana di Ingegneria Agraria, Ischia Porto, 12-16 settembre 2009.

Gonzalez R., Wood R., Digital imagine processing, Prentice Hall, Second edition, 2002, Upper Saddle River, New Jersey.

ISTAT. Quinto Censimento dell'Agricoltura. Istituto Nazionale di Statistica, 2000, Roma.

Jupiter S.D., Potts D.C., Phinn S.R., Duke N.C., Natural and anthropogenic changes to mangrove distributions in the Pioneer River Estuary (QLD, Australia). Wetlands Ecology and Management, 2007, 15, 1, 51-62. 
Langley S.K., Cheshire H.M., Humes K.S., A comparison of single date and multitemporal satellite image classifications in a semi-arid grassland. Journal of Arid Environments, 2001, 49, 401-411.

Leone A., Distante C., De Bernart M., Vasanelli L, Palazzo M. Sistema automatico per il conteggio di alberi di ulivo da immagini telerilevate (Automatic system for olive tree count from remote-sensing images). Proceedings of the X Conference ASITA, $14^{\text {th }}-17^{\text {th }}$ November 2006, Bolzano.

Li Z.Q., Khananian A., Fraser R.H., Cihlar J., Automatic detection of fire smoke using artificial neural networks and threshold approaches applied to AVHRR imagery. IEEE Transactions on Geoscience and Remote Sensing, 2001, 39, 1859-70.

Lunetta R.S., Ediriwickrema J., Johnson D.M., Lyon J.G., McKerrow A., Impacts of vegetation dynamics on the identification of land-cover change in a biologically complex community in North Carolina, USA. Remote Sensing of Environment, 2002, 82, 258-270.

Marques de Sá, J P. Pattern Recognition. Concepts, Methods and Application. Springer, 2001.

Rogge, E., Nevense, F., Gulinck, H. 2008. Reducing the visual impact of 'greenhouse parks' in rural landscape. Landscape and urban planning. 87, 76-83.

Sönmez N.K., Sari M., Use of remote sensing and geographic information system technologies for developing greenhouse databases. Turkish journal of agriculture and forestry, 2006, 30 (6), 413-420.

Sugiura R., Noguchi N., Ishii K., Remote-sensing technology for vegetation monitoring using an unmanned helicopter. Biosystem Engineering, 2005, 90(4), 369-379.

Townsend P.A., Walsh S., Remote sensing of forested wetlands: application of multitemporal and multispectral satellite imagery to determine plant community composition and structure in southeastern USA. Plant Ecology, 2001, 157, 129-149.

Wang Q., Adikua S., Tenhunena J., Granier A., On the relationship of NDVI with leaf area index in a deciduous forest site. Remote Sensing of Environment, 2005, 94, 244-255.

Wuest B., Zhang Y., Region based segmentation of QuickBird multispectral imagery through band ratios and fuzzy comparison. ISPRS Journal of Photogrammetry and Remote Sensing, 2009, 64, 55-64.

Zhao G.X., Li J., Li T, Yue Y., Warner T., Utilizing Landsat TM Imagery to Map Greenhouses in Qingzhou, Shandong Province, China. Pedosphere. 2004, 14(3), 1-7.

\section{SUMMARY}

Image processing is a powerful tool apt to perform selective data extraction from high-content images. In agricultural studies, image processing has been applied to different scopes, among them the classification of crop shelters has been recently considered especially in areas where there is a lack of public control in the building activity. The application of image processing to crop-shelter feature recognition make it possible to automatically produce thematic maps that constitute a basic knowledge for local authorities to cope with environmental problems and for technicians to be used in their planning activity.

This paper reviews the authors' experience in the definition of methodologies, based on the main image processing methods, for crop-shelter feature extraction from aerial digital images. Some experiences of pixel-based and object-oriented methods are described and discussed. The results show that the methodology based on object-oriented methods improves crop-shelter classification and reduces computational time, compared to pixel-based methodologies.

Keywords: greenhouse; image processing; pixelbased method; object-oriented method. 
